\title{
Seismic Design Concepts: Integration into the Curriculum
}

\author{
Lisa Wipplinger \\ Kansas State University
}

\begin{abstract}
This paper discusses earthquake hazards in the United States and how economic and social risk can be reduced by educating undergraduate engineering, architecture and construction students about earthquake forces and basic seismic design principles.
\end{abstract}

\section{Introduction}

Continuing studies and advances in seismology and geology have expanded seismicity information for the United States. These studies have confirmed that earthquake hazards are present throughout the United States, not just in California. Earthquakes in parts of the country other than California have often been treated as anomalies, but work in these areas shows a pattern of seismic activity. Large and moderate earthquakes occur more frequently in California than in other areas of the country, but other areas may have a higher risk of damage, death and injury because of the lack of preparation and awareness. Figure 1 shows a map prepared by the United States Geological Survey that indicates the current estimated earthquake hazard throughout the United States. The map represents the maximum ground acceleration that is estimated to have a 10 percent chance of being exceeded in that area in any 50 years.

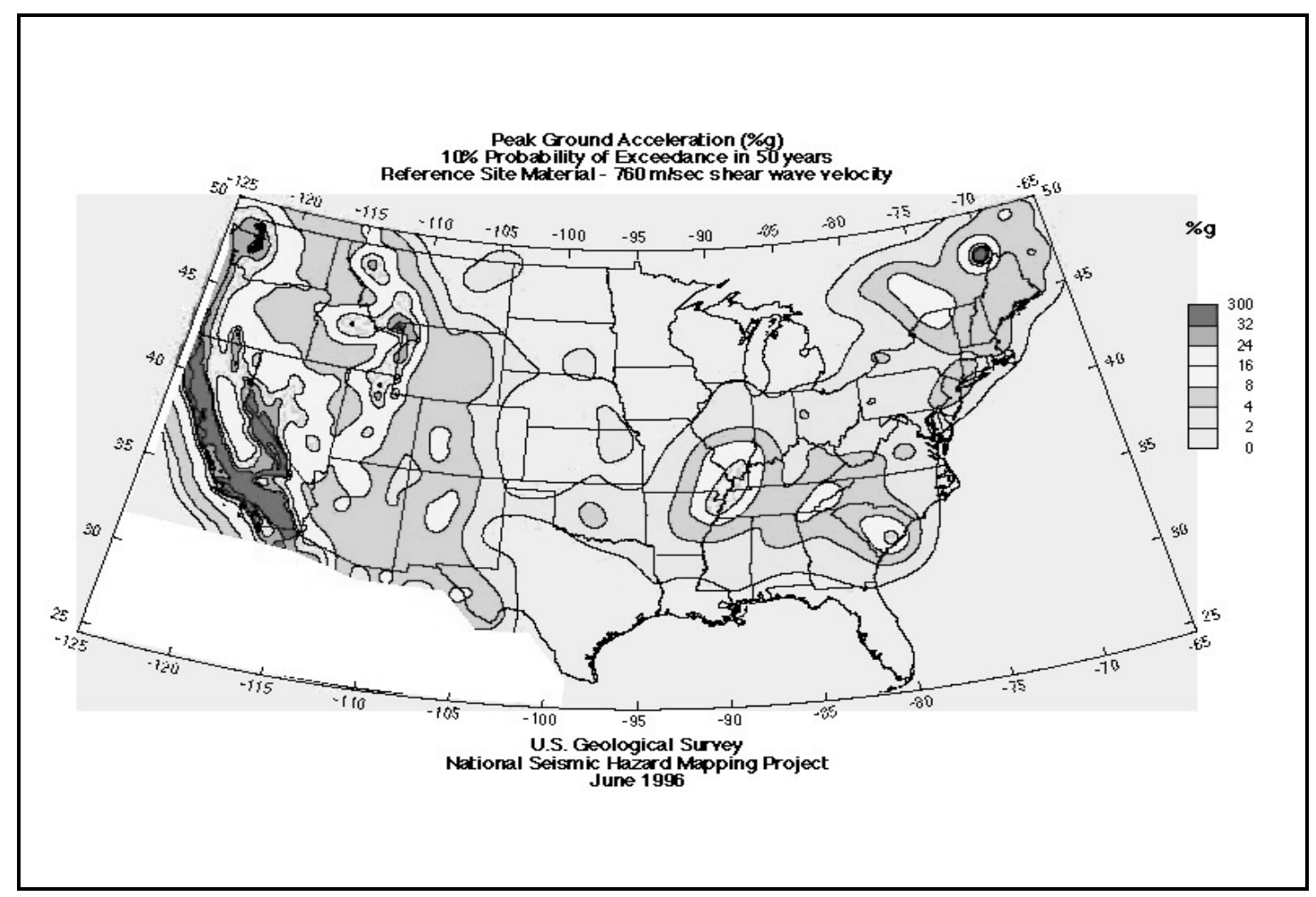

Figure 1: United States Earthquake Hazard 
Reducing the risk associated with earthquake hazards requires planning, public education and awareness. This process includes educating undergraduate students who will be involved in designing and building structures and infrastructure. Engineering, architecture and construction students should be familiar with the concepts involved in seismic design and need a basic understanding of the variables that affect a structure's performance under lateral loading.

\section{Important Concepts}

Considering the effects of lateral loads on structures requires evaluating the load paths and stability provided in the structure. This process improves understanding of the structure's behavior as a system and highlights some of the key concepts for providing a structure that will perform well under all types of loading. A good structural system should provide complete, direct load paths to transfer all design loads from their point of origin into the foundations. Considering loads applied in all directions, rather than just gravity loads acting down, often reveals weaknesses in the load path. Positive connections which tie the structure together vertically and horizontally so that it acts as a unit will greatly improve the performance under wind and seismic loading. This is especially important in wood and masonry construction.

In addition to continuity, the shape, size and configuration of a structure affect its response to different types of loads and its performance when subjected to those loads. This is especially true for dynamic loads, including seismic forces. Structures which deviate from a simple symmetrical system, are more vulnerable to sustaining damage under dynamic loads. Irregular building shapes with re-entrant corners create stress concentrations at the joint. Buildings with discontinuous or unbalanced structural systems will also have stress concentrations and may be subjected to torsional forces. Providing a design that does not have irregularities will reduce the risk of damage or collapse of the structure. If an irregularity cannot be avoided, it is important to recognize the most vulnerable part of the structure so it can be addressed in the design. Figure 2 illustrates some common types of building irregularities ${ }^{2}$.

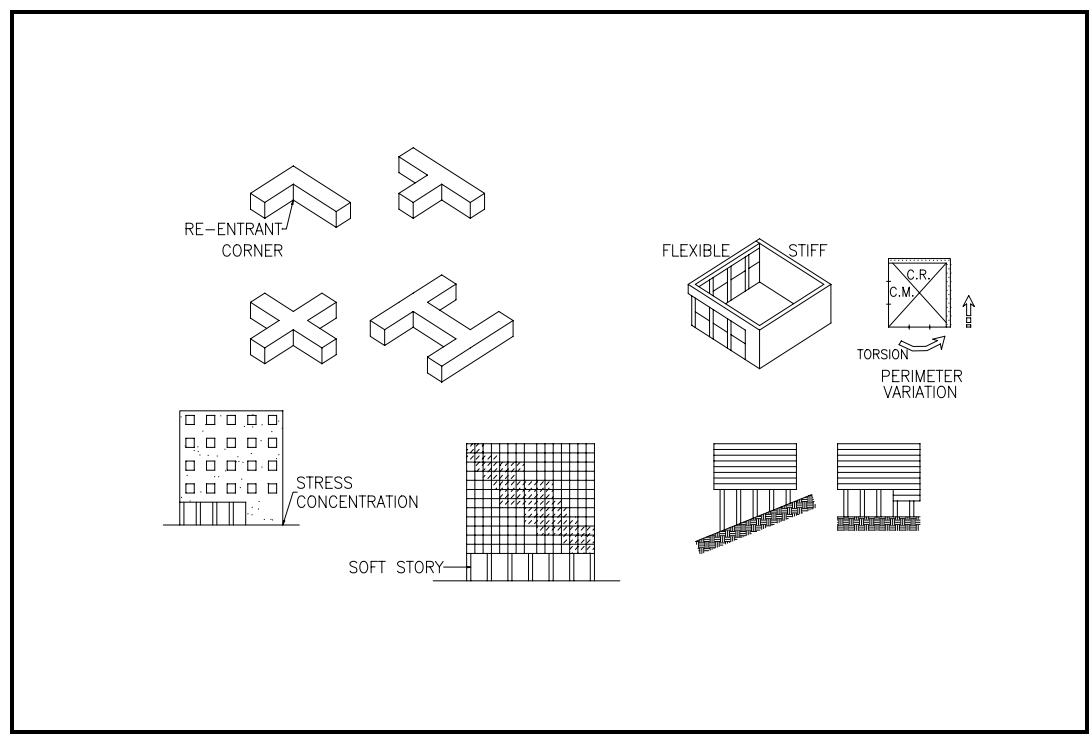

Figure 2: Irregular Building Configurations 
It is important to introduce the principles of seismic design to all students who will be involved in the building industry, not just structural engineers. Many smaller structures are designed and built without the involvement of a structural engineer and building plans are often checked by code officials without a background in structures or seismic design.

The simple principles of continuity, symmetry and redundancy do not require a great deal of engineering knowledge and may be achieved without significantly increasing the cost of a building. The principles are simple, but the improvement in the building's seismic performance will be significant and will likely reduce injuries and fatalities in a large earthquake.

The majority of damage in many earthquakes is caused by nonstructural items such as mechanical and electrical equipment, lights, ducts, piping, ceilings and wall panels falling, overturning, or being dislodged. Damage related to these items causes economic loss and increases the risk of persons being injured in an earthquake. Designers should be aware of this and think about where these items are located and how they are attached to the structure.

\section{Force Calculations}

Provisions for earthquake design first appeared in the 1927 Uniform Building Code in California and have evolved from their simple beginnings to the more complex procedures and provisions found in today's three primary model codes. The Uniform Building Code (UBC), National Building Code (NBC) and Standard Building Code (SBC) are currently being consolidated into one model code, the International Building Code (IBC), which will be used throughout the United States. The seismic provisions in the IBC will be based on the National Earthquake Hazards Reduction Program (NEHRP) 1997 Recommended Provisions for Seismic Regulations for New Buildings (not yet released). The current model codes are all based on a past edition of the NEHRP Provisions with some modifications. A model building code does not become law until it is adopted by a government agency, which is always free to adopt a revised version.

Building code requirements and enforcement are not uniform across the country, but the key design concepts are generally the same. Seismic forces for small and moderately-sized regular structures are calculated using the Equivalent Lateral Force Procedure, which is a static force procedure based on Newton's Second Law, $F=m a$. A seismic base shear, $V$, is calculated and then distributed over the height of the building to approximate the story shears caused by the structure's fundamental vibration mode. The 1994 NEHRP Recommended Provisions ${ }^{1}$ multiplies the weight of the structure by a seismic design coefficient, which represents the acceleration the structure will experience, to determine the seismic base shear:

$$
V=C_{s} W \quad C_{s}=\frac{1.2 C_{v}}{R T^{2 / 3}} \leq 2.5 C_{a}
$$

The seismic design coefficient, $C_{s}$, includes the effects of the expected input ground acceleration, the softness of the soil, the building's fundamental period, and the type of structural system. The effects of these variables are included as follows:

$$
C_{v} \text { and } C_{a} \text { combine the mapped acceleration value } A_{v} \text { or } A_{a} \text { with the soil }
$$


profile type, giving higher values for softer soils

$R$ is a response modification factor that reduces the design force based on the ductility and expected performance of the structural system. Specially designed ductile moment frames are assigned higher $R$ values than masonry walls because they are more ductile and are expected to hold together better when subjected to an earthquake. Systems that can be loaded significantly beyond their elastic capacity without collapsing are given high $R$ values.

$T$ is the estimated fundamental period of the building. A rough estimate of the period may be calculated using:

$$
\begin{aligned}
& T=C_{T} h_{n}{ }^{3 / 4} \\
& C_{T}=.035 \text { for steel moment frames } \\
& C_{T}=.030 \text { for concrete moment frames and eccentrically } \\
& \text { braced steel frames } \\
& C_{T}=.020 \text { for all other systems } \\
& \text { Or } \\
& T=0.1 N \\
& N=\text { number of stories }
\end{aligned}
$$

The base shear is distributed over the height of the building according to the weight tributary to each level and its height above the base of the building:

$$
\begin{gathered}
F_{x}=C_{v x} V \quad C_{v x}=\frac{w_{x} h_{x}^{k}}{\sum_{i=1}^{n} w_{i} h_{i}^{k}} \\
V=\text { design base shear } \\
w_{i} \text { or } w_{x}=\text { weight tributary to level } \mathrm{i} \text { or } \mathrm{x} \\
h_{i} \text { or } h_{x}=\text { height of level i or } \mathrm{x} \text { from the base }
\end{gathered}
$$

The base shear, $V$, and story forces, $F_{x}$, are used to design the lateral force resisting system and to check the overall stability of the building. The lateral force resisting system consists of horizontal diaphragms or braces that transfer the lateral loads to vertical resisting elements such as shear walls, braced frames or moment-resisting frames. Each vertical system has different characteristics and levels of effectiveness. Shear walls and braced frames provide stiffer systems which limit lateral deflections, but generally do not provide as much ductility as momentresisting frames. Moment-resisting frames also provide more architectural flexibility.

It is important to note the design forces as calculated above do not represent the maximum expected forces. In a strong earthquake the structure is expected to be stressed beyond its elastic strength without collapsing. This makes the ductility and connections of the structure very 
important. An earthquake will quickly find the weakest link in the structure, which should be able to deform without breaking to avoid a partial or total collapse.

Calculations may also be made for individual elements of structures and for nonstructural items such as equipment, lights, ceilings and wall panels. The design seismic force generated by these elements may be calculated using:

$$
\begin{aligned}
F_{p}= & 4.0 C_{a} I_{p} W_{p} \\
& C_{a} \text { is the seismic coefficient at grade based on the type of element } \\
& \text { and its location. } \\
& I_{p} \text { is the component importance factor } \\
& W_{p} \text { is the component operating weight }
\end{aligned}
$$

Individual elements and pieces of equipment should be anchored and braced as necessary to resist the lateral force, $F_{p}$, applied at the center of mass of the element or equipment.

The previous is intended to be a brief outline of seismic design calculations and requirements. A more detailed description of the seismic calculations and design requirements may be found in the 1994 NEHRP Provisions ${ }^{1}$.

\section{Integration Into the Curriculum}

Lateral load design principles need to be thoroughly integrated into the curriculum. Thorough integration requires discussion in more than one class. The basic principles outlined can be woven into analysis and design classes and applied in detail in a capstone course.

The idea of seismic design should be introduced in classes covering the history of building construction. Seismic design has evolved in response to structures being destroyed and damaged in earthquakes and is an important aspect of the history of building construction in the United States and around the world. After the students have been introduced to earthquakes, the concept of seismic forces and how they are calculated could then be introduced in structural analysis classes. Teaching students where forces come from and how they are calculated will enhance their understanding of how the forces are applied and how they affect the structure. Seismic design concepts provide an important tool for looking at stability and understanding structural system behavior.

Structural design classes can continue the process by including seismic loads in member design and by showing how the pieces fit together and contribute to the whole system. Design classes in other areas may include discussions about what happens to nonstructural items in an earthquake. Examples of past damage and effective anchorage details will enable students to think about the interactions between all the building's systems. The capstone course can then be used to reinforce these concepts and bring them all together. 


\section{Conclusion}

The economic and public ramifications of an earthquake induced disaster in the United States clearly point to the need for action to minimize the risk. Evidence shows seismic hazards are present in much of the United States, but they have not been adequately addressed in most areas. A major earthquake in any metropolitan area of the U.S. would have economic impacts far beyond the damaged area. Earthquake risk is a national issue and must be addressed as such.

Lessening the future risk of loss of property and life in earthquakes requires knowledge. Universities are at the leading edge of knowledge and prepare undergraduate engineering, architecture and construction students for work all over the world. Graduates should be familiar with seismic design forces and how they are calculated and applied. Most importantly, students should understand how the structures resist these forces and what conditions may create a weak link.

\section{References}

1. BSSC, NEHRP Recommended Provisions for Seismic Regulations for New Buildings, 1994 Edition, 2 volumes and maps, Building Seismic Safety Council, Washington, D.C., 1994.

2. BSSC , A Nontechnical Explanation of the 1994 NEHRP Recommended Provisions, 1995, Building Seismic Safety Council, Washington, D.C., 1995.

\section{Author Biography}

Lisa Wipplinger is a registered professional and structural engineer and an Instructor in the Department of Architectural Engineering and Construction Science at Kansas State University teaching structures courses. Member of ASCE, the Structural Engineers Association of Washington and EERI. Professional work has included multistory building design and seismic analysis and retrofit. 